combining the effects of exercise and isoprenaline he has derived an index of lability which gives an indication of how much the airways resistance, and probably the calibre of the bronchi, are likely to vary from time to time in an individual patient. On the basis of lability index he divides his patients into three groups: those with slightly reduced resting F.E.V..$_{1}$ and a slightly increased lability ; those with a slightly reduced resting F.E.V. ${ }_{1}$ but a greatly raised lability; and those with a much reduced resting F.E.V..$_{1}$ and very variable amount of lability. The full clinical significance of this grouping has yet to be worked out in practice, but it certainly serves a useful purpose in drawing attention to the great differences between different asthmatic children. Perhaps the greatest usefulness of the lability index will come in assessing the likely response to treatment and in detecting the chronic asthmatic.

An ever-present problem in the management of asthma in childhood lies in prognosis. Most patients experience a great improvement at puberty, perhaps related to their pubertal growth spurt. But in some children the asthma persists, and in others it recurs after a variable latent period which may last for many years. ${ }^{5}$ How can the physician predict which patients are likely to recover completely at puberty and which are liable to relapse ? How many adult patients with bronchitis and chronic respiratory insufficiency are former childhood asthmatics who have experienced a latent phase ?

The answer to these questions must come from the study of the latent phase in asthma. Drs. R. H. Trefor Jones and R. S. Jones describe (at p. 976 this week) a finding which may be very useful in detecting which asthmatics remain susceptible to further trouble, although symptom-free at the time. Apparently a fall in F.E.V..$_{1}$, sometimes rather large, takes place on exercise in adults with a history of childhood asthma. It remains to be seen how much prognostic significance should be attached to this finding. At the very least a means has been found of detecting an abnormality during this latent phase of asthma. Perhaps factors other than exercise will now be found which affect ventilatory function in a similar way during this phase. Study of these factors may begin to tell us why the remission does not always last, and how to prevent relapse.

The discovery that the bronchi remain abnormally susceptible, like the persistence of eosinophilia during remissions, reinforces the impression derived from the strong family pattern of the disease that asthma is primarily an inborn defect, the expression of which at any one time depends on environmental and psychological circumstances.

\section{Unemployment and Suicide}

To lose his job is one of the greatest blows that can befall a man. Many are likely to have this experience as a result of the measures which the Government considers necessary for the country's economic salvation. Is our country adequately prepared to minimize the harm that these actions taken for its collective well-being may do to the individual ?

Though obvious difficulties surround any attempt to measure the effect on a person's health of prospective or actual

\footnotetext{
Cobb, S., Brooks, G. W., Kasl, S. V., and Connelly, W. E., Amer. 7. publ. Hlth, 1966, 56, 1476.

2 East, W. N., F. ment. Sci., 1913, 59, 528.

3 Ewinscow, D., Brit. med. F., 1951, 1, 1417.

- Sainsbury, P., Suicide in London, 1955, Maudsley Monograph No. 1. London.

stengel, E., and Cook, N. G., Attempted Suicide, 1958, Maudsley Monograph No. 4. London.
}

C unemployment, a long-term study of this kind has been started in the U.S.A. and is the subject of a recent report ${ }^{1}$ that goes no further so far than describing the methodology. The persons being studied are male factory workers in Michigan who are married and have at least three years' seniority. The main cause of their unemployment appears to be the introduction of automation into the factories. Clearly this must have a bearing on the British scene, for automation is coming here just as it already has, to a more advanced degree, in the U.S.A. Consequently the results of this study will be awaited with great interest.

That unemployment may be an important cause of suicide was a conclusion W. Norwood East ${ }^{2}$ reached after studying some statistics for the years 1903-12 in England and Wales. The statistics for unemployment were at that time very incomplete. Better figures became available later, and D. Swinscow ${ }^{3}$ used these to show a remarkably close relationship from 1923 to 1947 between numbers of suicides and numbers of unemployed among the male population of Great Britain. The correlation ratio in fact was +0.93 . He concluded that " unemployment among men, or the society of which it is a feature, probably influences the suicide rate among men considerably." The corresponding statistical relationship was much less close for females. A study of suicide in London by $\mathrm{P}$. Sainsbury ${ }^{4}$ showed a higher rate among unemployed than employed people, and the case reports suggested that loss or lack of employment predisposed to suicide. The author also considered that "both suicide and unemployment are separate consequences of a common cause-a general social disturbance."

The causes of suicide in a multifarious society like ours are certainly highly diverse, and in a single individual may be complex, ${ }^{5}$ so that unemployment in itself when present as part of the cause may be acting very indirectly. It is also possible that mentally infirm people are more apt to lose their jobs in times of social upheaval than their more stable brethren. In any case the coming months will impose strains on individual patients that medical men may be able to detect and mitigate.

\section{Chicken-pox Pneumonia}

Though chicken-pox is usually a benign disease, its lesions in some viscera can occasionally cause serious trouble. ${ }^{1}$ A. F. Knyvett ${ }^{2}$ has recently given a report on pulmonary lesions. The liver, adrenal glands, and spleen may all be attacked, and in 1940 H. N. Johnson ${ }^{3}$ gave a detailed necropsy report of disseminated chicken-pox. In $1942 \mathrm{~J}$. J. Waring and his colleagues ${ }^{4}$ gave the first report of lesions in the lung, and by 1963 upwards of 120 cases of chicken-pox pneumonia had been reported. J. B. Mackay and P. Cairney have reported nodular pulmonary calcifications thought to be due to chicken-pox suffered in earlier adult life, and E. W. Abrahams and his colleagues ${ }^{6}$ have described calcification developing seven years after primary chicken-pox pneumonia.

In primary chicken-pox pneumonia the condition of the patient (who is more often adult than child) may after several uneventful days deteriorate. Pleuritic pain, cough, and

\footnotetext{
Brit. med. ₹., 1965, 2, 954.

Knyvett, A. F., Quart. F. Med., 1966, 35, 313.

4 Waring, J. J., Neubuerger, K., and Geever, E. F., Arch. intern. Med., $1942,69,384$

Mackay, J. B., and Cairney, P., N.Z. med. F., 1960, 59, 453.

Abrahams, E.'W., Evans, C., Knyvett, A. F., and Stringer, R. E., Med. f. Aust., 1964, 2, 781.
} 